IBIMA Publishing

Obstetrics \& Gynecology: An International Journal

http://www.ibimapublishing.com/journals/GYNE/gyne.html

Vol. 2015 (2015), Article ID 931113, 3 pages

DOI: $10.5171 / 2015.931113$

Research Article

\title{
Port Site Metastatic Disease in Ovarian Carcinoma
}

\author{
Robert O' Sullivan, Rizmee Shireen, Mohd Mat Samuji Swafani and Andrew \\ Curtain
}

Department of Gynecology, South Infirmary, Victoria University Hospital, Cork, Ireland

Correspondence should be addressed to: Robert O’ Sullivan; Robbie25@gmail.com

Received date: 22 January 2014; Accepted date: 27April 2014; Published date: 23 December 2015

Academic Editor: Nasuh Utku Doğan

Copyright (C) 2015. Robert O’ Sullivan, Rizmee Shireen, Mohd Mat Samuji Swafani and Andrew Curtain. Distributed under Creative Commons CC-BY 4.0

\begin{abstract}
Port site metastases are a recognised complication of laparoscopy in the presence of malignancy. With the increased use of minimally invasive technology to surgically manage gynecological malignancy, their incidence is likely to increase. Three encountered cases of port site metastatic disease are discussed. We recommend that consideration be given towards removing port sites when performing cyto-reductive surgery for gynecological malignancy.
\end{abstract}

Keywords: Port site, metastases, ovarian carcinoma

\section{Introduction}

The use of laparoscopy as both diagnostic and therapeutic resource is increasing. In patients with gynaecological malignancy, there is a risk of metastatic spread to the port sites. Here, we present three cases where patients had diagnostic laparoscopy prior to referral to the gyne-oncology centre. Metastatic disease at the port sites developed rapidly.

\section{Cases}

\section{Patient one}

A 56 year old patient attended a secondary centre complaining of abdominal pain and urinary incontinence. Computerized tomography demonstrated ascites, omental thickening and normal ovaries. Laparoscopy revealed an omentum and peritoneum with secondary tumour seeding and a suspicious left ovary that was not removed.

Following transfer to the tertiary gyneoncology centre a laparotomy and cytoreductive surgery was performed, nineteen days after the laparoscopy. The laparoscopic ports appeared abnormal with significant swelling under each port site. These were excised and sent along with both ovaries and a large portion of the omentum to the pathology department.

The underlying histology of both ovaries and omentum identified a poorly differentiated adenocarcinoma displaying a solid type growth pattern with focal serous

Cite this Article as: Robert O’ Sullivan, Rizmee Shireen, Mohd Mat Samuji Swafani and Andrew Curtain 
papillary differentiation. Histological assessment was performed upon biopsies taken of all three port sites. In each, metastatic adenocarcinoma was present.

\section{Patient Two}

A sixty-five year old lady underwent laparoscopy after presenting with abdominal pain. Biopsies of omentum, right ovary and peritoneum were obtained. Peritoneal fluid was taken for cytological assessment, which was positive for poorly differentiated serous adenocarcinoma, in keeping with the other biopsies. Following this, care was transferred to the tertiary centre.

Laparotomy and cyto-reductive surgery was performed seventeen days later. During the surgery, large areas of edema were noted on the anterior abdominal wall at all the three port sites and these were excised. Histological assessment favoured a probable primary serous carcinoma of the right fallopian tube.

Histology of the port site biopsies revealed infiltrating high grade serous adenocarcinoma with desmoplastic and sclerotic stromal reaction and marked pleomorphism, in keeping with the underlying tumour.

\section{Patient Three}

A sixty year old patient developed abdominal pain with vomiting and attended a secondary centre, where she was admitted under the care of the surgical team. Pre-operative imaging demonstrated ascites, pelvic mass and poorly defined mass adjacent to the bladder suggestive of peritoneal deposit. Laparoscopy was undertaken and biopsy of tumour deposit sent for histology, with ascitic fluid sent for cytology. These specimens contained adenocarcinoma, most likely ovarian in origin.

The patient underwent laparotomy performed twenty-three days later. The omentum was replaced with metastatic tumour and sheets of metastatic disease present in the pelvis and pouch of Douglas, in addition to a small amount of ascites. A nodule was felt beneath the umbilicus and this was removed. This was shown to contain metastatic high grade serous papillary adenocarcinoma, in keeping with the underlying diagnosis.

\section{Discussion}

The use of laparoscopy and its application in the management of gynaecological malignancy is increasing as stated by Liu et al (2009). Port site metastases were first described in a case involving ovarian carcinoma by Dobronte et al (1978).

Zivanovic et al (2008) estimated the overall incidence to be approximately $1.18 \%$, and it was noted that in most instances of port site disease, other metastases are also present. The exact mechanism is unknown. Sooriakumaran et al (2009) regarded the aggressiveness of the tumour as the greatest risk for port site metastases. Suggested mechanisms include direct wound implantation, chimney effect, aerosolisation of tumour cells and pneumoperitoneum. Excessive tumour handling and contamination of instruments is also thought by Gutt et al (1999) to contribute. Topical use of oxaliplatin at the port sites was shown by Yun-Sheng Tai et al (2006) not to be preventative against metastases. A case series by Berretta et al (2009) found that port site metastases did not occur in borderline ovarian tumours.

The early development of port site metastases has been described by Ozman et al (2011) in patients receiving neoadjuvant chemotherapy for ovarian cancer. In our cases, the metastases occurred whilst the patients were awaiting tumour removal. The rate of port site metastases in robotic surgery for gynecological malignancy is similar, reported at $1.1 \%$ by Ndofor et al (2011). The incidence of port site involvement in cervical and uterine malignancies is much lower, estimated at $0.43 \%$ by Martinez et al (2010). The effect that port site metastatic disease has upon prognosis is unclear. In a study by Vergote (2005), there was no effect upon prognosis in a cohort of thirty patients with ovarian malignancy when compared with one 
hundred and forty one patients who did not have port site metastases. In this study, however, a large number of the patients received port site excision at the time of debulking surgery.

\section{Conclusions}

In these three cases of the port site metastases developed rapidly and were clinically suspected at the time of laparotomy. We recommend, based upon these cases where a patient has recently undergone laparoscopy, that consideration be given towards removing the port sites. We also recommend that the debulking surgery should occur as soon as possible.

\section{References}

1. Berretta R, Rolla $M$, Patrelli TS, Gramellini D, Fadda GM, Nardelli GB (2009): Incidence of port-site metastasis after laparoscopic management of borderline ovarian tumours: Eur J Gynaecol Oncol.; 30(3):300-2

2. Dobronte Z, Wittmann T, Karacsony G (1978) 'Rapid development of malignant metastases in the abdominal wall after laparoscopy'. Endoscopy; 10: 127-130

3. Gutt CN, Riemer V, Kim ZG, Jacobi CA, Paulucci V, Lorenz M (1999) 'Impact of laparoscopic colonic resection on tumour growth and spread in an experimental model'. Br J Surg; 86: 1180-1184

4. Liu CS, Nagarsheth NP, Nezhat FR (2009) 'Laparoscopy and ovarian cancer: a paradigm change in the management of ovarian cancer?' J Minim Invasive Gynecol May-Jun; 16(3):250-62

5. Martinez A, Querleu D, Leblanc E, Narducci F, Ferron G (2010), 'Low incidence of port site metastasis after laparoscopic staging of uterine carcinoma'; Gynecol Oncology; Aug 1:118(2) 145-50

6. Ndofor BT, Soliman PT, Schmeler KM, Nick AM, Frumovitz M, Ramirez PT (2011) 'Rate of port-site metastasis is uncommon in patients undergoing robotic surgery for gynaecological malignancies'; Int J gynecol Cancer Jul; 21(5): 936-40

7. Ozmen B, Sükür YE, Atabekoglu CS, Heper AO, Sonmezer M and Gungor M (2011) Early port-site metastasis during neoadjuvant chemotherapy in advanced stage ovarian cancer: Report of two cases: J Gynecol Oncol Vol. 22 No 1:57-60

8. Sooriakumaran P Kommu SS, Anderson C, Rane A (2009),' Port site metastases after laparoscopic surgery: what causes them and what can be done to reduce their incidence?' BJU Int. Mar; 103 (5): 701-2

9. Vergote I, Marquette S, Amant F, Berteloot P and Neven P, 2005 'Port-site metastases afer open laparoscopy: a study in 173 patients with advanced ovarian carcinoma', Int J Gynecol Cancer, 2005 SepOct;15(5):776-9

10. Yun-Sheng Tai, Abente FC, Assalia A, Ueda K and Gagner M (2006) 'Topical treatment with oxaliplatin for the prevention of port site metastases in laparoscopic surgery for colorectal cancer': Journal of the Society of Laparoendoscopic Surgeons 10:160-165

11. Zivanovic O, Sonoda Y, Diaz JP, Levine DA, Brown CL et al (2008) 'The rate of port site metastases after 2251 laparoscopic procedures in women with underlying malignant disease': Gynecol Oncol Dec 111(3):431-7 